Author affiliations appear at the end of this article.

Published online ahead of print at www.jco.org on December 2, 2013.

Written on behalf of the European Organisation for Research and Treatment of Cancer (EORTC) and Gruppo Italiano Malattie Ematologiche dell' Adulto (GIMEMA) Leukemia Groups.

Supported by the European Organisation for Research and Treatment of Cancer (EORTC) Charitable Trust.

Presented at the 53rd American Society of Hematology Annual Meeting and Exposition, San Diego, CA, December 10-13, 2011

Authors' disclosures of potential conflicts of interest and author contributions are found at the end of this article.

Clinical trial information: NCT00004128.

Corresponding author: Roelof Willemze MD, PhD, Department of Hematology, Leiden University Medical Center, Albinusdreef 2, Leiden, the Netherlands: e-mail: r.willemze@lumc.nl.

(C) 2013 by American Society of Clinical Oncology

0732-183X/14/3203w-219w/\$20.00 DOI: 10.1200/JCO.2013.51.8571

\title{
High-Dose Cytarabine in Induction Treatment Improves the Outcome of Adult Patients Younger Than Age 46 Years With Acute Myeloid Leukemia: Results of the EORTC-GIMEMA AML-12 Trial
}

Roelof Willemze, Stefan Suciu, Giovanna Meloni, Boris Labar, Jean-Pierre Marie, Constantijn J.M. Halkes, Petra Muus, Martin Mistrik, Sergio Amadori, Giorgina Specchia, Francesco Fabbiano, Francesco Nobile, Marco Sborgia, Andrea Camera, Dominik L.D. Selleslag, Francois Lefrère Sr, Domenico Magro, Simona Sica, Nicola Cantore, Meral Beksac, Zwi Berneman, Xavier Thomas, Lorella Melillo, Jose E. Guimaraes, Pietro Leoni, Mario Luppi, Maria E. Mitra, Dominique Bron, Georges Fillet, Erik W.A. Marijt, Adriano Venditti, Anne Hagemeijer, Marco Mancini, Joop Jansen, Daniela Cilloni, Liv Meert, Paola Fazi, Marco Vignetti, Silvia M. Trisolini, Franco Mandelli, and Theo de Witte

Listen to the podcast by Dr Arnason at www.jco.org/podcasts

$$
\begin{array}{llllllll}
\text { A } & \text { B } & \text { S } & \text { T } & \text { R } & \text { A } & \text { C } & \text { T }
\end{array}
$$

\section{Purpose}

Cytarabine plays a pivotal role in the treatment of patients with acute myeloid leukemia (AML). Most centers use 7 to 10 days of cytarabine at a daily dose of 100 to $200 \mathrm{mg} / \mathrm{m}^{2}$ for remission induction. Consensus has not been reached on the benefit of higher dosages of cytarabine.

\section{Patients and Methods}

The European Organisation for Research and Treatment of Cancer (EORTC) and Gruppo Italiano Malattie Ematologiche dell' Adulto (GIMEMA) Leukemia Groups conducted a randomized trial (AML-12; Combination Chemotherapy, Stem Cell Transplant and Interleukin-2 in Treating Patients With Acute Myeloid Leukemia) in 1,942 newly diagnosed patients with $A M L$, age 15 to 60 years, comparing remission induction treatment containing daunorubicin, etoposide, and either standard-dose (SD) cytarabine $\left(100 \mathrm{mg} / \mathrm{m}^{2}\right.$ per day by continuous infusion for 10 days) or high-dose (HD) cytarabine $\left(3,000 \mathrm{mg} / \mathrm{m}^{2}\right.$ every 12 hours by 3-hour infusion on days $1,3,5$, and 7). Patients in complete remission (CR) received a single consolidation cycle containing daunorubicin and intermediate-dose cytarabine (500 mg/m² every 12 hours for 6 days). Subsequently, a stem-cell transplantation was planned. The primary end point was survival.

\section{Results}

At a median follow-up of 6 years, overall survival was $38.7 \%$ for patients randomly assigned to SD cytarabine and $42.5 \%$ for those randomly assigned to HD cytarabine (log-rank test $P=.06$; multivariable analysis $P=.009$ ). For patients younger than age 46 years, survival was $43.3 \%$ and $51.9 \%$, respectively ( $P=.009$; multivariable analysis $P=.003)$, and for patients age 46 to 60 years, survival was $33.9 \%$ and $32.9 \%$, respectively $(P=.91)$. CR rates were $72.0 \%$ and $78.7 \%$, respectively $(P<.001)$ and were $75.6 \%$ and $82.4 \%$ for patients younger than age 46 years $(P=$ $.01)$ and $68.3 \%$ and $74.8 \%$ for patients age 46 years and older $(P=.03)$. Patients of all ages with very-bad-risk cytogenetic abnormalities and/or FLT3-ITD (internal tandem duplication) mutation, or with secondary AML benefitted from HD cytarabine.

\section{Conclusion}

HD cytarabine produces higher remission and survival rates than SD cytarabine, especially in patients younger than age 46 years.

\section{J Clin Oncol 32:219-228. (C) 2013 by American Society of Clinical Oncology}

\section{INTRODUCTION}

Cytarabine plays an important role in the treatment of patients with acute myeloid leukemia (AML). Administration at a daily dose of 100 to $200 \mathrm{mg} / \mathrm{m}^{2}$ for 7 to 10 days in combination with 3 days of an anthracycline is the most commonly used remission induc- tion regimen. This schedule results in complete remission (CR) rates of $60 \%$ to $80 \%$ depending on age and cytogenetic and molecular features of the acute leukemia. ${ }^{1,2}$ Higher doses of cytarabine (2,000 to $6,000 \mathrm{mg} / \mathrm{m}^{2}$ per day for eight to twelve doses) for induction of remission and/or in consolidation have been tested in various AML trials. ${ }^{3-17}$ Thus far, four 
randomized trials have been reported that evaluated increased dosages of cytarabine as part of the induction regimen of previously untreated patients. ${ }^{14-17}$ Despite these experiences, definite conclusions on the value of high-dose (HD) cytarabine remain hard to draw. Possible reasons are insufficient numbers of patients per trial or more intensive induction strategies in the control arm. ${ }^{13}$ On the basis of the encouraging results of the Australian Leukemia Study Group reported by Bishop et al, ${ }^{14}$ the Leukemia Groups of the European Organisation for Research and Treatment of Cancer (EORTC) and the Gruppo Italiano Malattie Ematologiche dell' Adulto (GIMEMA) conducted a large randomized trial (AML-12; Combination Chemotherapy, Stem Cell Transplant and Interleukin-2 in Treating Patients With Acute Myeloid Leukemia) to compare HD cytarabine versus standard-dose (SD) cytarabine in the induction regimen. In both arms, patients who achieved CR after one or two induction courses received a single consolidation course containing intermediate-dose cytarabine and allogeneic or autologous stem-cell transplantation (SCT).

\section{PATIENTS AND METHODS}

\section{Eligibility}

Untreated patients with de novo or secondary AML age 15 to 60 years were eligible. Main inclusion criteria were morphologically confirmed AML with bone marrow containing $30 \%$ or more blasts; a WHO performance status of 3 or less; no evidence of severe concurrent cardiac, pulmonary, neurologic, or metabolic disorders or uncontrolled infections; and adequate liver and renal function tests. Secondary AML was defined as AML following hematologic or

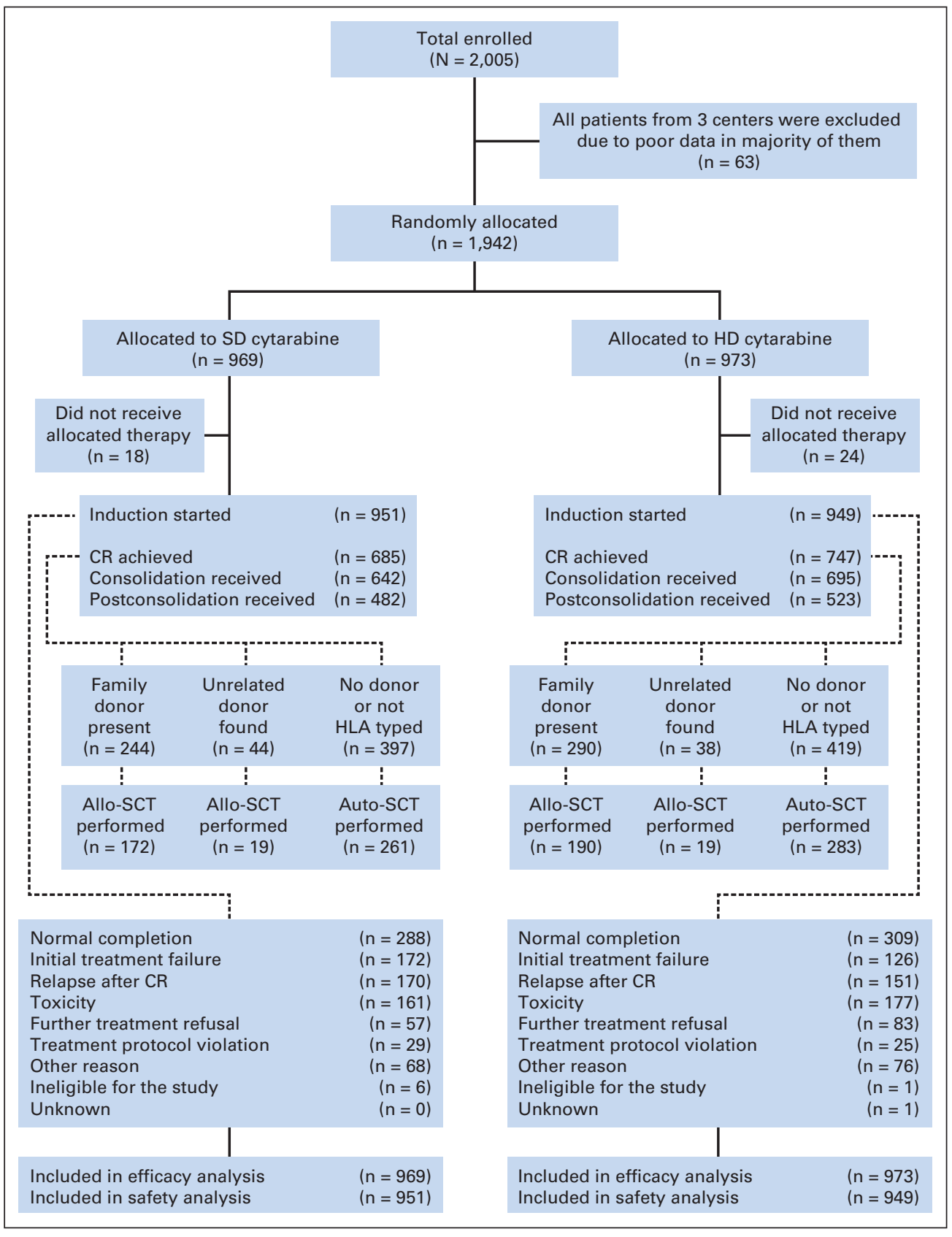

Fig 1. Disposition of patients in each arm. Allo-SCT; allogeneic stem-cell transplantation; auto-SCT, autologous SCT; CR, complete remission; $\mathrm{HD}$, high dose; $\mathrm{SD}$, standard dose. 
nonhematologic malignancies or after exposure to chemotherapy or radiation. Patients with promyelocytic leukemia, AML after myelodysplastic syndrome of more than 6 months duration, or AML/blast crisis after chronic myeloproliferative disease or during concomitant other progressive malignant disease were excluded (Fig 1).

The study was approved by the internal review boards of EORTC and GIMEMA and the ethical committee of each participating institution and was conducted in accordance with the Declaration of Helsinki. All patients signed the informed consent form.

\section{Study Design}

The study aimed to compare efficacy and toxicity of an induction regimen that contained HD cytarabine versus SD cytarabine. Primary end point was overall survival (OS). Secondary end points were CR rate, disease-free survival (DFS), toxicity, and rate of autologous or allogeneic SCT in each arm. Patients who fulfilled the eligibility criteria were randomly assigned to the standard or experimental arm at the EORTC Headquarters in Brussels, Belgium. At random assignment, patients were stratified according to center, age ( 15 to 45 years $v 46$ to 60 years), WHO performance status (grade 0 to $1 v$ grade $2 v$ grade 3$)$, and total leukocyte count $\left(<25 v 25\right.$ to $\left.99.9 v \geq 100 \times 10^{9} / \mathrm{L}\right)$ by using a minimization technique (Fig 2 ).

The basis for our standard remission induction regimen was the standard arm of the EORTC-GIMEMA Study AML-10 (Daunorubicin Versus Mitoxantrone Versus Idarubicin As Induction and Consolidation Chemotherapy for Adults With Acute Myeloid Leukemia: The EORTC and GIMEMA Groups Study AML-10), ${ }^{2}$ which included daunorubicin, etoposide, and 10 days of cytarabine. At that time, the standard arm in the AML-10 trial showed the lowest toxicity with equal efficacy compared with the experimental arms. Furthermore, this schedule had important similarities with the standard arm of the Australian trial. ${ }^{14}$ In the experimental arm, 4 days of HD cytarabine replaced the 10 days of SD cytarabine similar to the experimental arm of the Australian trial. Thus, remission induction consisted of daunorubicin (50 $\mathrm{mg} / \mathrm{m}^{2}$ per day as a 5 -minute intravenous [IV] infusion on days 1,3 , and 5) and etoposide ( $50 \mathrm{mg} / \mathrm{m}^{2}$ per day by 1-hour IV infusion on days 1 through 5) in both arms, in combination with either 10 days of cytarabine $\left(100 \mathrm{mg} / \mathrm{m}^{2} \mathrm{per}\right.$ day as continuous IV infusion) in the standard arm (SD cytarabine) or cytarabine $\left(3,000 \mathrm{mg} / \mathrm{m}^{2}\right.$ every 12 hours as a 3-hour IV infusion on days 1, 3, 5, and $7)$ in the experimental arm (HD cytarabine). Assessment of response was planned by day 31 of induction. Criteria for response and relapse followed the Report of the National Cancer Institute-Sponsored Workshop. ${ }^{18}$ In case of partial remission, a second identical induction course was given. Once CR with

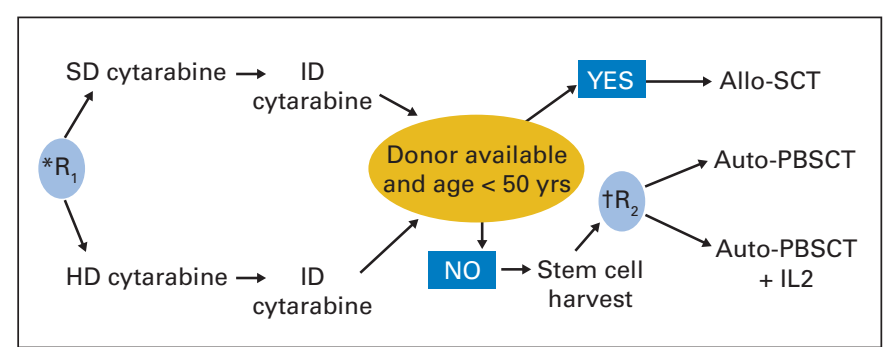

Fig 2. Trial design of the European Organisation for Research and Treatment of Cancer/Gruppo Italiano Malattie Ematologiche dell' Adulto (EORTC-GIMEMA) AML-12 trial. Treatment schedules are as follows: standard-dose (SD) cytarabine induction: daunorubicin $\left(50 \mathrm{mg} / \mathrm{m}^{2}\right.$ per day as a 5 -minute intravenous [IV] infusion on days 1,3 , and 5) plus etoposide $\left(50 \mathrm{mg} / \mathrm{m}^{2}\right.$ per day by 1 -hour IV infusion on days 1 through 5) plus 10 days of cytarabine (100 mg/m² per day as continuous IV infusion); high-dose (HD) cytarabine induction: daunorubicin $\left(50 \mathrm{mg} / \mathrm{m}^{2}\right.$ per day as a 5 -minute IV infusion on days 1,3 , and 5$)$ plus etoposide $\left(50 \mathrm{mg} / \mathrm{m}^{2}\right.$ per day by 1 -hour IV infusion on days 1 through 5) plus cytarabine $\left(3,000 \mathrm{mg} / \mathrm{m}^{2}\right.$ every 12 hours as a 3-hour IV infusion on days 1, 3, 5, and 7); intermediate-dose (ID) cytarabine consolidation: cytarabine $\left(500 \mathrm{mg} / \mathrm{m}^{2}\right.$ every 12 hours as a 2-hour IV infusion on days 1 through 6) plus daunorubicin $\left(50 \mathrm{mg} / \mathrm{m}^{2}\right.$ per day as a 5 -minute infusion on days 4 through 6). Allo-SCT, allogeneic stem-cell transplantation; auto-PBSCT, autologous peripheral blood SCT; IL-2, interleukin-2 $\left(4 \times 10^{6} \mathrm{IU} / \mathrm{m}^{2}\right.$ subcutaneous injection on day $1+8 \times 10^{6} \mathrm{IU} / \mathrm{m}^{2}$ subcutaneous injections on days 2 through 5 , every 4 weeks, for 1 year). $\left(^{*}\right) R_{1}$, first randomization; $(\dagger) R_{2}$, second randomization. or without full hematologic recovery was achieved, a single consolidation course identical with the consolidation course of EORTC-GIMEMA AML$10,{ }^{2}$ consisting of intermediate-dose cytarabine $\left(500 \mathrm{mg} / \mathrm{m}^{2}\right.$ every 12 hours as a 2-hour IV infusion on days 1 through 6) plus daunorubicin $\left(50 \mathrm{mg} / \mathrm{m}^{2}\right.$ per day as a 5-minute infusion on days 4 through 6) was administered. In some centers, allogeneic SCT (allo-SCT) was strongly recommended after consolidation for patients younger than age 50 years or up to age 60 years with an HLA-compatible family donor, or for patients without a family donor who had AML with chromosome abnormalities involving 3q, 5, t(6;9), t $(9 ; 22)$, 7, or 11 q23 complex abnormalities, or for those with a matched unrelated donor who needed a second remission induction course. All patients not eligible for allo-SCT were planned for autologous SCT. Mobilization and collection of autologous stem cells of those patients was scheduled during the recovery phase of consolidation. Lenograstim $\left(150 \mu \mathrm{g} / \mathrm{m}^{2}\right.$ per day) was given by daily subcutaneous injections from day 20 of consolidation until completion of the blood stem-cell harvest. All CR patients without a suitable stem-cell donor were eligible for a second random assignment involving 5 days of low-dose subcutaneous interleukin-2 as monthly courses for a year or until relapse. Results of the second random assignment are not within the scope of this report.

\section{End Points}

OS was defined as the time interval from random assignment until death, whatever the cause. Follow-up of patients still alive was censored at the moment of last visit or contact. DFS was defined as the time from CR until the first relapse or death as a result of any cause. For patients still alive in first CR, DFS was censored on the date of last visit or contact. Because allo-SCT was integrated into the treatment scheme, follow-up of patients was not censored at the date of allo-SCT. Event-free survival (EFS) for patients in CR was defined as DFS, whereas for patients who did not reach CR, EFS was set as being an event at time zero. The duration of hematologic recovery was defined as the time from the first day of the chemotherapy course until neutrophil level was more than $0.5 \times 10^{9} / \mathrm{L}$ or platelet level was more than $10 \times 10^{9} / \mathrm{L}$ or more than $100 \times 10^{9} / \mathrm{L}$; patients without recovery were censored at day 99 . Toxicity was evaluated according to Common Toxicity Criteria version 2.0.

\section{Statistical Analysis}

The study was powered to detect an $8 \%$ treatment difference (from $35 \%$ to $43 \%$ ) in the 5 -year OS rate, corresponding to a hazard ratio (HR) of 0.80 (two-sided $\alpha, 5 \%$; power, $95 \%$ ) and a treatment-age ( 15 to $45 v 46$ to 60 years) interaction with an $80 \%$ power. A total of 2,000 randomly assigned patients was required to follow 1,100 of them until death.

Time-to-event outcomes were computed by using the Kaplan-Meier technique and were compared by using the two-tailed log-rank test. ${ }^{19} \mathrm{Cumu}$ lative incidence of relapse and of the incidence of death in CR were estimated by using competing risk methods. ${ }^{19}$ Forest plot technique was used to obtain treatment HR estimate, along with its $95 \%$ or $99 \%$ CI, and to perform subgroup analyses. The Cox proportional hazards model stratified by cytogenetic-molecular features was used to adjust the treatment comparison by initial patient-disease features. Fisher's exact test and linear logistic regression model were used to compare the $\mathrm{CR}$ rates after induction.

All efficacy analyses were performed according to the intention-to-treat principle (all patients randomly assigned were included, except for all patients $[n=63]$ from three centers with extremely poor data reporting). To avoid selection bias, analysis of the impact of allo-SCT on the outcome was performed according to the availability of a donor, and treatment comparison regarding DFS was performed separately in patients with and without a donor. Data for patients who started the protocol treatment were used for response rate, EFS, and adverse event comparison, and data for patients who reached CR were used for DFS and time-to-recovery comparisons. SAS 9.3 software (SAS Institute, Cary, NC) was used for the statistical analyses.

\section{RESULTS}

\section{Patients}

Between September 1999 and January 2008, 1,942 patients were randomly assigned: 872 from 22 EORTC and 1,070 from 42 GIMEMA 
Table 1. Baseline Characteristics of all Patients, Patients Age 15-45 Years, and Patients Age 46-60 Years, by Randomized Treatment Arm

\begin{tabular}{|c|c|c|c|c|c|c|c|c|c|c|c|c|}
\hline \multirow[b]{3}{*}{ Characteristic } & \multicolumn{4}{|c|}{ All Patients } & \multicolumn{4}{|c|}{ Patients Age $15-45$ Years } & \multicolumn{4}{|c|}{ Patients Age 46-60 Years } \\
\hline & \multicolumn{2}{|c|}{$\begin{array}{l}\text { SD Cytarabine } \\
(\mathrm{n}=969)\end{array}$} & \multicolumn{2}{|c|}{$\begin{array}{c}H D \\
\text { Cytarabine } \\
(n=973)\end{array}$} & \multicolumn{2}{|c|}{$\begin{array}{c}\text { SD Cytarabine } \\
(n=490)\end{array}$} & \multicolumn{2}{|c|}{$\begin{array}{c}H D \\
\text { Cytarabine } \\
(\mathrm{n}=490)\end{array}$} & \multicolumn{2}{|c|}{$\begin{array}{c}\text { SD Cytarabine } \\
(\mathrm{n}=479)\end{array}$} & \multicolumn{2}{|c|}{$\begin{array}{c}H D \\
\text { Cytarabine } \\
(\mathrm{n}=483)\end{array}$} \\
\hline & No. & $\%$ & No. & $\%$ & No. & $\%$ & No. & $\%$ & No. & $\%$ & No. & $\%$ \\
\hline Male sex & 504 & 52 & 508 & 52.2 & 244 & 49.8 & 252 & 51.4 & 260 & 54.3 & 256 & 53.6 \\
\hline \multicolumn{13}{|l|}{ Age, years } \\
\hline Median & \multicolumn{2}{|c|}{45} & \multicolumn{2}{|c|}{45} & \multicolumn{2}{|c|}{36} & \multicolumn{2}{|c|}{34} & \multicolumn{2}{|c|}{54} & \multicolumn{2}{|c|}{53} \\
\hline Range & \multicolumn{2}{|c|}{$15-60$} & \multicolumn{2}{|c|}{$15-60$} & \multicolumn{2}{|c|}{$15-45$} & \multicolumn{2}{|c|}{$15-45$} & \multicolumn{2}{|c|}{$46-60$} & \multicolumn{2}{|c|}{$46-60$} \\
\hline WHO performance status $0-1$ & 871 & 89.9 & 872 & 89.6 & 438 & 89.4 & 454 & 92.7 & 433 & 90.4 & 418 & 86.5 \\
\hline \multicolumn{13}{|l|}{ Type of leukemia } \\
\hline De novo AML & 906 & 93.5 & 919 & 94.5 & 466 & 95.1 & 470 & 95.9 & 440 & 91.9 & 449 & 93 \\
\hline Secondary AML & 58 & 6 & 47 & 4.8 & 22 & 4.5 & 17 & 3.5 & 36 & 7.5 & 30 & 6.2 \\
\hline \multicolumn{13}{|l|}{ WBCs at diagnosis $\times 10^{9} / \mathrm{L}$} \\
\hline$<25$ & 566 & 58.4 & 574 & 59 & 270 & 55.1 & 282 & 57.6 & 296 & 61.8 & 292 & 60.5 \\
\hline $25-99.9$ & 287 & 29.6 & 283 & 29.1 & 147 & 30 & 149 & 30.4 & 140 & 29.2 & 134 & 28.5 \\
\hline$\geq 100$ & 116 & 12 & 116 & 11.9 & 73 & 14.9 & 59 & 12 & 43 & 9 & 57 & 11.8 \\
\hline Median & \multicolumn{2}{|c|}{16.3} & & & & & & & & & & \\
\hline Range & & & & & & & & & & & & \\
\hline FLT3-ITD mutation & & & & & & & & & & & & \\
\hline Negative & 487 & 50.3 & 469 & 48.2 & 252 & 51.4 & 244 & 49.8 & 235 & 49.1 & 225 & 46.6 \\
\hline Positive & 126 & 13.0 & 137 & 14.1 & 68 & 13.9 & 68 & 13.9 & 58 & 12.1 & 69 & 14.3 \\
\hline Not done & 356 & 36.7 & 367 & 37.7 & 170 & 34.7 & 178 & 36.3 & 186 & 38.8 & 189 & 39.1 \\
\hline Cytogenetics/FLT3-ITD* & & & & & & & & & & & & \\
\hline Good risk & 97 & 10 & 93 & 9.6 & 70 & 14.3 & 65 & 13.3 & 27 & 5.6 & 28 & 5.8 \\
\hline Intermediate risk & 287 & 29.6 & 260 & 26.7 & 140 & 28.6 & 119 & 24.3 & 147 & 30.7 & 141 & 29.2 \\
\hline Bad risk & 107 & 11 & 94 & 9.7 & 61 & 12.4 & 61 & 12.4 & 64 & 13.4 & 74 & 15.3 \\
\hline Very bad risk/FLT3-ITD & 223 & 23 & 256 & 26.3 & 106 & 21.6 & 101 & 20.6 & 95 & 19.8 & 114 & 23.6 \\
\hline Unknown risk & 255 & 26.3 & 270 & 27.7 & 109 & 22.2 & 144 & 29.4 & 146 & 30.5 & 126 & 26.1 \\
\hline Donor availability in CR patients only & 685 & & 747 & & 366 & & 399 & & 319 & & 348 & \\
\hline No donor present & 330 & & 338 & & 182 & & 187 & & 148 & & 151 & \\
\hline Family donor present & 244 & & 290 & & 137 & & 157 & & 107 & & 133 & \\
\hline Unrelated donor present & 44 & & 38 & & 31 & & 29 & & 13 & & 9 & \\
\hline No HLA typing & 67 & & 81 & & 16 & & 26 & & 51 & & 55 & \\
\hline $\begin{array}{l}\text { Abbreviations: AML, acute myeloid le } \\
\text { "Good risk includes the abnormalities } \\
\text { bad risk/FLT3-ITD includes presence of } \\
\text { abnormalities were pooled into a separ } \\
\text { together as "unknown risk." }\end{array}$ & "bad i & $\begin{array}{l}\text { omplet } \\
8 ; 21) . \text { In } \\
-7 / 7 q- \\
\text { " cytoge }\end{array}$ & nissic & $\begin{array}{l}\text { HD, hig } \\
\text { sk inclu } \\
\text { ormalit } \\
\text { up. Pa }\end{array}$ & $\begin{array}{l}3 \mathrm{l}, \mathrm{t}(6 \\
\mathrm{s} \text { with }\end{array}$ & $\begin{array}{l}\text { t(9;22) } \\
\text { known }\end{array}$ & $\begin{array}{l}\text { dem } d \\
\text { and the } \\
11 q 2 \\
\text { t done }\end{array}$ & $\begin{array}{l}\text { cation; } \\
\text { with - } \\
\text { nd all } p \\
\text { unsuc }\end{array}$ & $\begin{array}{l}\text { stano } \\
\text { nly, wi } \\
\text { nts wit } \\
\text { sful cy }\end{array}$ & $\begin{array}{l}\text { dose. } \\
\text { ut FLT3 } \\
\text { i FLT3-I } \\
\text { enetic t }\end{array}$ & $\begin{array}{l}\text { mutat } \\
\text { mutati } \\
\text { s were }\end{array}$ & $\begin{array}{l}\text { Very } \\
\text { Other } \\
\text { ouped }\end{array}$ \\
\hline
\end{tabular}

centers. Their median age was 45 years (range, 15 to 60 years). As induction, 969 patients were randomly assigned to receive the SD cytarabine and 973 to receive the HD cytarabine regimen. The two treatment arms were matched with respect to baseline characteristics (Table 1). Fifty-three randomly assigned patients were ineligible-25 $(2.6 \%)$ in the SD cytarabine and $28(2.9 \%)$ in the HD cytarabine arm-but they were included in the main intention-to-treat analysis. Reasons for ineligibility were wrong diagnosis (acute lymphoblastic leukemia, chronic myeloblastic leukemia, acute promyelocytic leukemia, or myelodysplastic syndrome in 40 patients and other reasons in 13 patients.

\section{Treatment Phases and Outcomes}

A total of 1,900 patients started induction treatment: 951 in the SD cytarabine and 949 in the HD cytarabine arm (Fig 1). Reasons for not starting induction were refusal $(\mathrm{n}=4)$, death before treatment $(\mathrm{n}=10)$, ineligibility $(\mathrm{n}=21)$, and other $(\mathrm{n}=7)$. Details regarding treatment phases and outcomes in both randomly assigned arms are shown in Table 2. A significantly higher percentage of patients receiv- ing HD cytarabine achieved CR $(P=.009)$. The death rate after one or two induction courses was similar in both arms. Among 1,432 patients who achieved CR, consolidation course was administered to 1,337 patients: $93.7 \%$ in the SD cytarabine arm and $93.0 \%$ in the HD cytarabine arm. Reasons for not receiving consolidation were death before treatment $(n=7)$, no longer in CR $(n=14)$, persisting infection $(n=34)$, persisting organ failure $(n=7)$, neurologic toxicity $(\mathrm{n}=7)$, and other $(\mathrm{n}=26)$.

At a median follow-up of 6 years, 1,091 patients had died: 568 $(59.7 \%)$ in the SD cytarabine arm and 523 (55.2\%) in the HD cytarabine arm. The OS rate at 6 years was $40.6 \%$ for all patients: $38.7 \%$ in the SD cytarabine arm and $42.5 \%$ in the HD cytarabine arm (HR, 0.89; $P=.06)$. Comparison of treatment outcome stratified for cytogenetic features and adjusted for several other risk factors was significant in favor of HD cytarabine (HR, 0.86; $P=.009$; Fig 3A).

\section{Subgroup Analysis}

Planned subgroup analyses according to age group were performed for different end points (Tables 2 and 3, Fig 3B and Fig 4). Both 


\begin{tabular}{|c|c|c|c|c|c|c|c|c|c|c|c|c|}
\hline \multirow[b]{3}{*}{ Induction Treatment } & \multicolumn{4}{|c|}{ All Patients } & \multicolumn{4}{|c|}{ Patients Age $15-45$ Years } & \multicolumn{4}{|c|}{ Patients Age 46-60 Years } \\
\hline & \multicolumn{2}{|c|}{ SD Cytarabine } & \multicolumn{2}{|c|}{ HD Cytarabine } & \multicolumn{2}{|c|}{ SD Cytarabine } & \multicolumn{2}{|c|}{ HD Cytarabine } & \multicolumn{2}{|c|}{ SD Cytarabine } & \multicolumn{2}{|c|}{ HD Cytarabine } \\
\hline & No. & $\%$ & No. & $\%$ & No. & $\%$ & No. & $\%$ & No. & $\%$ & No. & $\%$ \\
\hline Patients who started induction & 951 & 100 & 949 & 100 & 484 & 100 & 484 & 100 & 467 & 100 & 465 & 100 \\
\hline CR after one course & 649 & 68.2 & 715 & 75.3 & 351 & 72.5 & 380 & 78.5 & 298 & 63.8 & 335 & 72 \\
\hline CR after one or two courses & 685 & 72 & 747 & 78.7 & 366 & 75.6 & 399 & 82.4 & 319 & 68.3 & 348 & 74.8 \\
\hline Resistant disease & 180 & 18.9 & 126 & 13.3 & 78 & 16.1 & 50 & 10.3 & 96 & 20.6 & 70 & 15.1 \\
\hline Death during induction phase & 86 & 9 & 74 & 7.8 & 34 & 7.0 & 27 & 5.5 & 52 & 11.1 & 47 & 10.1 \\
\hline Consolidation treatment (eligible) & 685 & 100 & 747 & 100 & 366 & 100 & 399 & 100 & 319 & 100 & 348 & 100 \\
\hline Patients who started consolidation & 642 & 93.7 & 695 & 93 & 346 & 94.5 & 372 & 93.2 & 296 & 92.8 & 323 & 92.8 \\
\hline Postconsolidation treatment & 482 & 75.1 & 523 & 75.5 & 268 & 77.5 & 288 & 77.4 & 214 & 72.3 & 235 & 72.7 \\
\hline Autologous SCT & 261 & & 283 & & 135 & & 149 & & 126 & & 134 & \\
\hline Intensive chemotherapy & 30 & & 31 & & 13 & & 18 & & 17 & & 13 & \\
\hline Allogeneic SCT (related donor) & 172 & & 190 & & 108 & & 104 & & 64 & & 86 & \\
\hline Allogeneic SCT (unrelated donor) & 19 & & 19 & & 12 & & 17 & & 7 & & 2 & \\
\hline \multicolumn{13}{|l|}{ Outcome from first $\mathrm{CR}$} \\
\hline Still alive in first $C R$ & 292 & 42.6 & 339 & 45.4 & 172 & 47.0 & 214 & 53.6 & 120 & 37.6 & 125 & 35.9 \\
\hline Relapse & 321 & 46.9 & 315 & 42.2 & 164 & 44.8 & 157 & 39.3 & 157 & 49.2 & 158 & 45.4 \\
\hline Death in first $C R$ & 72 & 10.5 & 93 & 12.4 & 30 & 8.2 & 28 & 7.0 & 42 & 13.2 & 65 & 18.7 \\
\hline DFS rate at 6 years & & 41.6 & & 44.7 & & 46.4 & & 52.8 & & 35.8 & & 35.5 \\
\hline $\mathrm{HR}$ & \multicolumn{2}{|c|}{0.93} & \multicolumn{2}{|c|}{$\begin{array}{c}95 \% \mathrm{Cl}_{1} \\
0.81 \text { to } 1.06\end{array}$} & \multicolumn{2}{|c|}{0.83} & $\begin{array}{r}94 \\
0.6\end{array}$ & $\begin{array}{l}\mathrm{Cl} \\
1.08\end{array}$ & \multicolumn{2}{|c|}{1.03} & \multicolumn{2}{|c|}{$\begin{array}{c}99 \% \mathrm{Cl}_{1} \\
0.80 \text { to } 1.33\end{array}$} \\
\hline Log rank $P$ & \multicolumn{4}{|c|}{0.27} & \multicolumn{4}{|c|}{0.07} & \multicolumn{4}{|c|}{0.73} \\
\hline $\mathrm{HR}^{*}$ & \multicolumn{2}{|c|}{0.88} & \multicolumn{2}{|c|}{$\begin{array}{l}95 \% \mathrm{Cl}_{1} \\
0.77 \text { to } 1.01\end{array}$} & \multicolumn{2}{|c|}{0.79} & \multicolumn{2}{|c|}{$\begin{array}{c}99 \% \mathrm{Cl}_{1} \\
0.60 \text { to } 1.03\end{array}$} & \multicolumn{4}{|c|}{$\begin{array}{c}99 \% \mathrm{Cl} \\
0.77 \text { to } 1.27\end{array}$} \\
\hline Wald $P^{*}$ & \multicolumn{4}{|c|}{0.08} & \multicolumn{4}{|c|}{0.02} & \multicolumn{4}{|c|}{0.89} \\
\hline Relapse incidence at 6 years & & 47.9 & & 43.0 & & 45.3 & & 40.3 & & 51.1 & & 46.0 \\
\hline Death in $C R$ incidence at 6 years & & 10.5 & & 12.4 & & 8.3 & & 7.0 & & 13.1 & & 18.5 \\
\hline
\end{tabular}

age $(P=.06)$ and disease type (de novo $v$ secondary AML $P=.05)$ had an impact on treatment comparison regarding survival (Fig 4). For patients age 15 to 45 years, HD cytarabine significantly improved the CR rate $(82.4 \% v 75.6 \% ; P=.01)$, the 6-year EFS rate $(43.6 \% v 35.1 \%$; $P=.003)$, and the 6-year OS rate $(51.9 \% v 43.3 \% ; P=.009)$; in older patients, only the CR rate was higher in the HD cytarabine arm. In the younger age group, HD cytarabine increased the 6-year DFS rate compared with SD cytarabine $(52.8 \% v 46.4 \% ; P=.07)$ by decreasing the relapse incidence by $5 \%(40.3 \% v 45.3 \%)$ and without increasing the incidence of death in CR (Table 2). In contrast, in the older age group, the decrease of 5.1\% $(46.0 \% v 51.1 \%)$ in relapse incidence was counterbalanced by an increase of $4.6 \%(18.5 \% v 13.1 \%)$ in the incidence of death in CR (Table 2). Furthermore, in the younger age group, HD cytarabine improved OS more in patients with secondary AML (HR, 0.23; $P=.005)$ than in patients with de novo AML (HR, $0.83 ; P=.04)$.

Interestingly, improvement of the CR rate in patients with secondary AML was detected both in younger (odds ratio, 5.99) and in older patients (odds ratio, 3.75), as was the OS in patients with very-bad-risk cytogenetic abnormalities and/or FLT3-ITD (internal tandem duplication) mutation both in younger ( $\mathrm{HR}, 0.70 ; P=.02$ ) and older patients $(\mathrm{HR}, 0.80, P=.14)$. These findings were confirmed by multivariable analyses (Table 3 ), and also when eligible patients who started the allocated treatment were considered (data not shown).

\section{DFS According to Donor Availability and Age Group}

In the younger age group, availability of a family donor did improve the outcome in both randomly assigned arms. In the SD cytarabine arm, the 6-year DFS rate was $57.4 \%$ for patients with a donor and $39.5 \%$ for patients without a donor; in the HD cytarabine arm, the 6-year DFS rates were $62.6 \%$ and $46.4 \%$, respectively. The estimated treatment $\mathrm{HR}$ was 0.84 in patients with a donor and 0.83 in patients without a donor.

For the older age group, the 6-year DFS was approximately 35\% in patients with or without a family donor, whether they received HD or SD cytarabine. The estimated treatment HR was close to 1 in each group. Adding patients with unrelated donors to the group of patients with related donors did not significantly alter the treatment comparisons (data not shown).

\section{Adverse Events}

Grade 3 and 4 nonhematologic toxicities of the induction courses were not different in the two randomly assigned arms except for conjunctivitis grade 2 to 3 toxicity, which occurred more frequently in the HD cytarabine arm than in the SD cytarabine arm ( $12.4 \% v 0.5 \%)$. Grade 3 and 4 infectious complications were reported in $67.6 \%$ of patients receiving SD cytarabine and in $66.2 \%$ of those receiving HD cytarabine. In the two age groups ( 15 to 45 and 46 to 60 years), adverse event profiles in the two randomly assigned arms were remarkably similar. Median time to neutrophil recovery $\left(>0.5 \times 10^{9} / \mathrm{L}\right)$ after the 


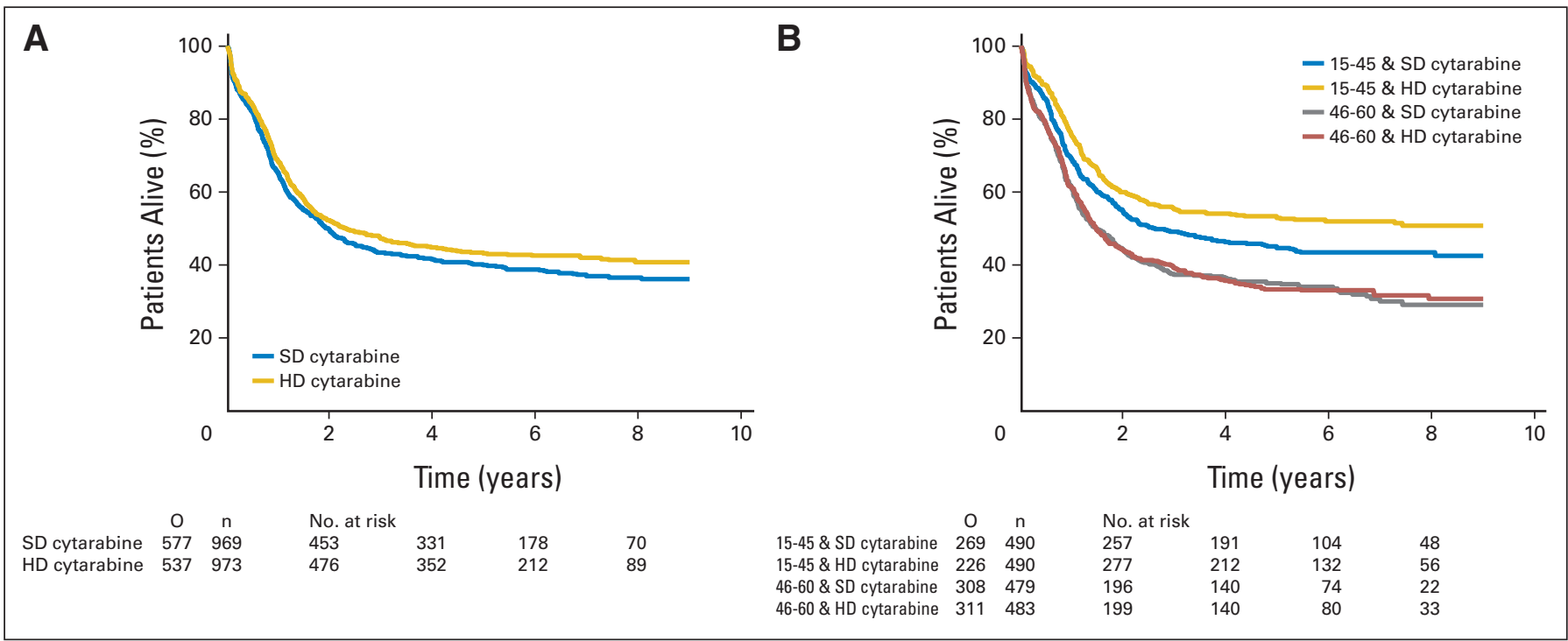

Fig 3. (A) Overall survival according to randomized arm. High-dose (HD) cytarabine versus standard-dose (SD) cytarabine hazard ratio, $0.89(95 \% \mathrm{Cl}, 0.79$ to $1.00 ; P=$ .06). Hazard ratio stratified for cytogenetics and adjusted by age, disease type, WBCs at diagnosis, performance status was $0.86(95 \% \mathrm{Cl}, 0.76$ to $0.96 ; P=.009)$. (B) Overall survival according to age and randomization arm. O, observed No. of deaths.

start of first induction course was 27 days in the SD cytarabine arm $v 25$ days in the HD cytarabine arm. Median times to platelet recovery $\left(>100 \times 10^{9} / \mathrm{L}\right)$ were 29 days in the SD cytarabine arm and 27 days in the HD cytarabine arm.

After the consolidation course, grade 3 to 4 nonhematologic toxicities were similar in both arms. Median time to neutrophil recovery $\left(>0.5 \times 10^{9} / \mathrm{L}\right)$ was 22 days in both arms. Median time to platelet recovery in the SD $v$ HD cytarabine arms was $20 v 22$ days to reach $10 \times 10^{9} / \mathrm{L}$ platelets and $31 v 38$ days to reach $100 \times$ $10^{9} / \mathrm{L}$ platelets.

\section{DISCUSSION}

This study demonstrates that at a median follow-up of 6 years in patients age 15 to 60 years with untreated AML, induction of remission using HD cytarabine in combination with daunorubicin and etoposide is associated with higher CR rate and survival chance than using the same regimen with SD cytarabine and without significant increase in toxicity. Survival advantage is significant for patients younger than age 46 years and for patients with secondary AML or with AML associated with very-bad-risk cytogenetic abnormalities or FLT3-ITD mutation.

Our results differ from previously published randomized trials on HD cytarabine in the induction regimen. ${ }^{14-17}$ Main differences are the number of induction cycles and the total doses of cytarabine administered before establishing treatment response and the number of patients per randomized arm (for details, see Appendix Table A1, online only). We were impressed by the results of the Australian Leukemia Study Group, ${ }^{14}$ which randomized remission induction with SD cytarabine and HD cytarabine, both combined with daunorubicin and etoposide, followed (in the case of CR) by two mild consolidation courses and 2 years of maintenance therapy. CR rates were $74 \%$ in the SD cytarabine arm and $71 \%$ in the HD cytarabine arm. Toxicity was significantly higher after HD cytarabine, and $18 \%$ of patients in the HD cytarabine arm died during induction compared with $11 \%$ in the SD cytarabine arm $(P=.09)$. For patients receiving HD cytarabine, significantly longer duration of remission, DFS, and survival for CR patients was reported. OS was not statistically different between the two arms. The relatively low number of patients included in the trial prevented further long-term analysis. We hypothesized that improvement in supportive care during induction together with availability of more intensive postremission strategies might decrease induction death and relapse rates. Furthermore, the inclusion of a larger number of patients would allow proper evaluation of a potential therapeutic advantage of HD cytarabine in induction therapy. On the basis of these arguments, we designed a large phase III study using both arms of the Australian protocol as well as the control arm of our most recent EORTC-GIMEMA AML-10 study.

In this study, stratification for age ( 15 to 45 and 46 to 60 years) at registration allowed profound statistical analysis in the two subgroups. In patients younger than age 46 , the beneficial effect of $\mathrm{HD}$ cytarabine induction was consistently and significantly observed in terms of CR rate, $\mathrm{EFS}$, and OS; in patients age 46 to 60 years, the positive effect of the increase in CR rate was counterbalanced by an increase in death in $\mathrm{CR}$, translating into a small improvement in OS. Younger patients were expected to fare better with intensive chemotherapy and transplantation than older patients. ${ }^{1,2}$ However, more intensive treatment and higher remission rates are usually not translated into longer survival. An age effect on survival was not reported by the Australian Leukemia Study Group. ${ }^{15}$ Only the HOVON-SAKK (Cytarabine Dose for Acute Myeloid Leukemia) study ${ }^{17}$ showed a trend in survival improvement in favor of HD cytarabine in patients younger than 36 years: $52 \%$ 5-year OS in the HD cytarabine arm and $42 \%$ in the intermediate-dose cytarabine arm (HR, $0.73, P=.14)$. Although the HOVON-SAKK study did not show major differences between the intermediate-dose and HD cytarabine arms, it remains an unanswered question whether a comparison between SD cytarabine and 


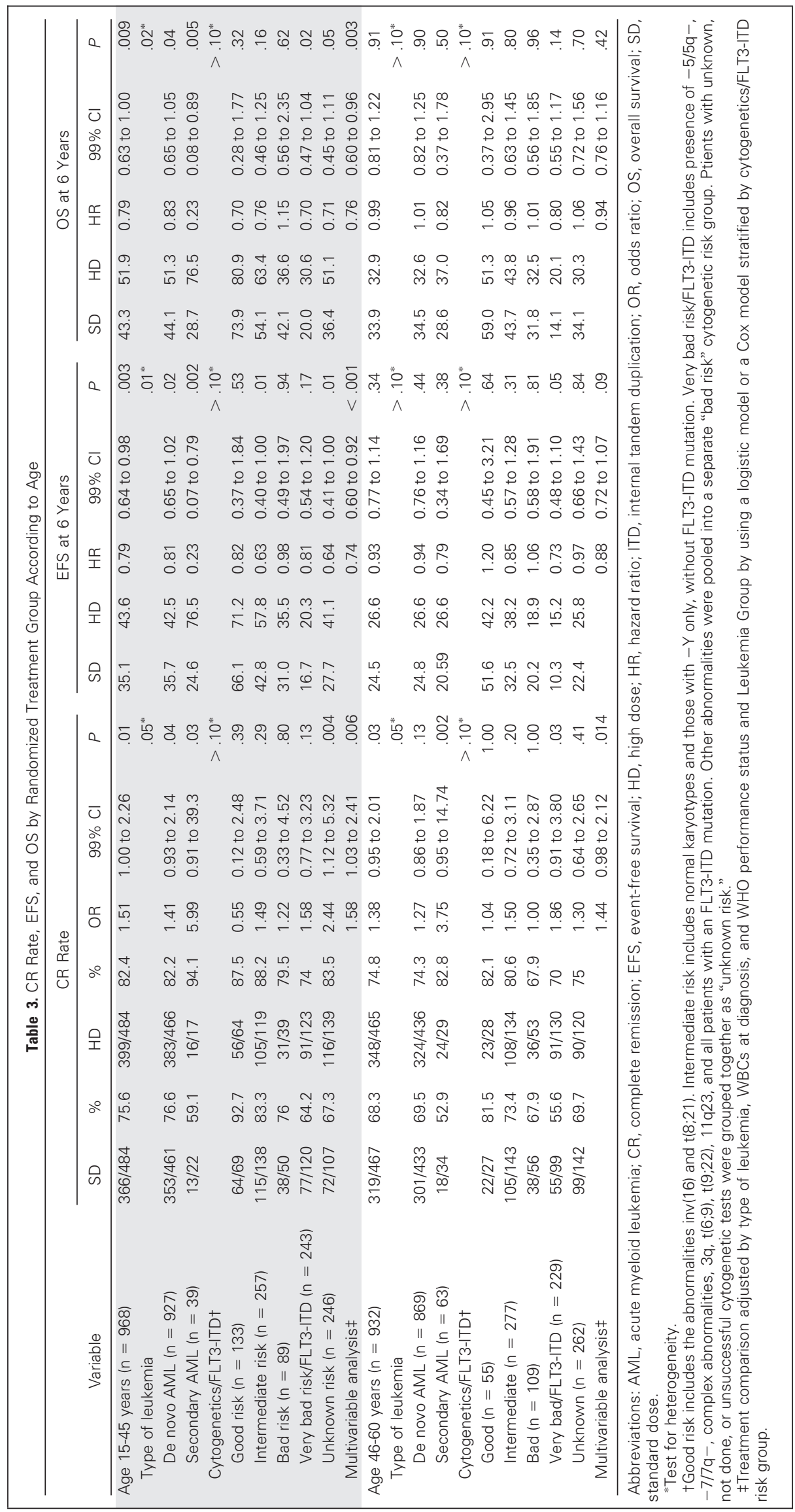




\begin{tabular}{|c|c|c|c|c|c|c|}
\hline HD-C & $\begin{array}{l}\text { Events/P } \\
\text { Cytarabine }\end{array}$ & $\begin{array}{l}\text { atients } \\
\text { SD-Cytarabine }\end{array}$ & $\begin{array}{l}\text { Stati } \\
(\mathrm{O}-\mathrm{E})\end{array}$ & $\begin{array}{l}\text { istics } \\
\text { Var. }\end{array}$ & $\begin{array}{c}\mathrm{HR} \& \mathrm{Cl}^{*} \\
\text { (HD-Cytarabine : SD-Cytarabind }\end{array}$ & $\mathrm{HR}(99 \% \mathrm{Cl})$ \\
\hline \multicolumn{7}{|l|}{ Age, years } \\
\hline $15-45$ & $226 / 490$ & $269 / 490$ & -28.9 & 123.5 & & $0.79(0.63$ to 1.00$)$ \\
\hline $46-60$ & $311 / 483$ & $308 / 479$ & -1.5 & 154.5 & & 0.99 (0.80 to 1.22$)$ \\
\hline \multicolumn{7}{|c|}{ Heterogeneity test $(\mathrm{df}=1): P=.06$} \\
\hline \multicolumn{7}{|l|}{ Type of leukemia } \\
\hline de novo AML & $511 / 919$ & $535 / 906$ & -21.8 & 261.1 & & 0.92 (0.78 to 1.08 ) \\
\hline sAML & $23 / 47$ & $40 / 58$ & -9.2 & 15.7 & & $0.56(0.29$ to 1.07$)$ \\
\hline \multicolumn{7}{|c|}{ Heterogeneity test $(\mathrm{df}=1): P=.05$} \\
\hline \multicolumn{7}{|l|}{ WBC, $\times 10^{9} / \mathrm{L}$} \\
\hline$<25$ & $318 / 574$ & $323 / 566$ & -12.2 & 159.9 & & $0.93(0.76$ to 1.14$)$ \\
\hline $25-99$ & $148 / 283$ & $174 / 287$ & -15.5 & 80.3 & & $0.82(0.62$ to 1.10$)$ \\
\hline$\geq 100$ & $71 / 116$ & $80 / 116$ & -3.3 & 37.6 & & 0.92 (0.60 to 1.39 ) \\
\hline \multicolumn{7}{|c|}{ Heterogeneity test $(\mathrm{df}=2): P>.1$} \\
\hline \multicolumn{7}{|l|}{ Cytogenetics } \\
\hline Good & $25 / 93$ & $31 / 97$ & -2.4 & 14 & & 0.84 (0.42 to 1.68$)$ \\
\hline Intermediate & $162 / 320$ & $198 / 351$ & -16.6 & 89.8 & & 0.83 (0.63 to 1.09$)$ \\
\hline Bad & 73/108 & $81 / 124$ & 3.5 & 38 & & $1.10(0.72$ to 1.66$)$ \\
\hline Very bad & $91 / 126$ & $83 / 104$ & -10.3 & 42.2 & & 0.78 (0.53 to 1.17$)$ \\
\hline Unknown & $186 / 326$ & $184 / 293$ & -12.8 & 91.8 & & 0.87 (0.67 to 1.14$)$ \\
\hline \multicolumn{7}{|c|}{ Heterogeneity test $(\mathrm{df}=4): P>.1$} \\
\hline \multicolumn{7}{|l|}{ Cytogenetics/FLT3-ITD } \\
\hline Good & $25 / 93$ & $31 / 97$ & -2.4 & 14 & & 0.84 (0.42 to 1.68$)$ \\
\hline Intermediate & $119 / 260$ & $141 / 287$ & -8.2 & 64.9 & & 0.88 (0.64 to 1.21$)$ \\
\hline Bad & $60 / 94$ & $67 / 107$ & 2.3 & 31.4 & & 1.08 (0.68 to 1.70$)$ \\
\hline Very bad/FLT3-ITD & $182 / 256$ & $180 / 223$ & -23.6 & 88.5 & & 0.77 (0.58 to 1.01$)$ \\
\hline Unknown & $151 / 270$ & $158 / 255$ & -12.5 & 76.8 & & 0.85 (0.63 to 1.14$)$ \\
\hline \multicolumn{7}{|c|}{ Heterogeneity test $(\mathrm{df}=4): P>.1$} \\
\hline \multirow[t]{4}{*}{ Total } & $\begin{array}{l}537 / 973 \\
(55.2 \%)\end{array}$ & $\begin{array}{l}577 / 969 \\
(59.5 \%)\end{array}$ & -31.7 & 278 & & $0.89(0.79 \text { to } 1.00)^{*}$ \\
\hline & & & & 0.25 & 2.0 & 4.0 \\
\hline & & & \multicolumn{4}{|c|}{ HD-cytarabine better } \\
\hline & & & & & Treatment effect: $P=.06$ & \\
\hline
\end{tabular}

Fig 4. Subgroup analyses of overall survival for high-dose (HD) cytarabine versus standarddose (SD) cytarabine in the intention-to-treat population. (*) $95 \% \mathrm{Cl}$ for totals and subtotals; 99\% Cl elsewhere. AML, acute myeloid leukemia; HR, hazard ratio; ITD, internal tandem duplication; O-E, observed-expected; sAML, secondary acute myeloid leukemia; Var., variance. intermediate-dose cytarabine in induction would have led to the same results as shown with HD cytarabine in our study.

In contrast to the significantly increased toxicity observed in earlier trials, ${ }^{14,15,17}$ except for significant conjunctivitis, we report that HD cytarabine, in the way it was administered as it was in our study, was not associated with higher toxicity including death during induction. As mentioned, this could reflect the inclusion of strict supportive guidelines in the treatment protocol. Longer duration of platelet recovery was documented only after the consolidation course. This finding has also been reported in the Australian Study, ${ }^{14}$ the EORTC-GIMEMA AML-10 trial $^{2}$ and the HOVON-SAKK trial, ${ }^{17}$ and may be as a result of increased stem-cell toxicity.

In the younger age group, donor versus no-donor analysis showed that availability of a donor improved the chances to remain alive in first CR equally in both randomized arms. In the older age group, a better antileukemic effect by allo-SCT may have been counterbalanced by a higher death rate as a result of transplantation complications. The number of transplantations using unrelated donor stem cells was too small to affect the results.

The planned subgroup analysis also showed clinically important superiority of HD cytarabine induction in patients with AML with very-bad-risk cytogenetic abnormalities, with FLT3-ITD mutation, and in patients with secondary AML. This is a particularly important finding since, thus far, only allo-SCT has been proven to favorably affect the dismal prognosis of these patients with bad-risk AML. ${ }^{20}$

In conclusion, HD cytarabine in the induction treatment of patients age 15 to 45 years with AML significantly increased response rate and survival without significant increase in grade 3 to 4 toxicities. 


\section{AUTHORS' DISCLOSURES OF POTENTIAL CONFLICTS} OF INTEREST

Although all authors completed the disclosure declaration, the following author(s) and/or an author's immediate family member(s) indicated a financial or other interest that is relevant to the subject matter under consideration in this article. Certain relationships marked with a " $U$ " are those for which no compensation was received; those relationships marked with a " $C$ " were compensated. For a detailed description of the disclosure categories, or for more information about ASCO's conflict of interest policy, please refer to the Author Disclosure Declaration and the Disclosures of Potential Conflicts of Interest section in Information for Contributors. Employment or Leadership Position: None Consultant or Advisory Role: Theo de Witte, Novartis (C) Stock Ownership: None Honoraria: Theo de Witte, Novartis Research Funding: Theo de Witte, Novartis Expert Testimony: None Patents: None Other Remuneration: None

\section{AUTHOR CONTRIBUTIONS}

Conception and design: Roelof Willemze, Stefan Suciu, Giovanna Meloni, Jean-Pierre Marie, Constantijn J.M. Halkes, Petra Muus, Martin Mistrik, Sergio Amadori, Giorgina Specchia, Francesco Nobile, Marco Sborgia, Dominik L.D. Selleslag, Francois Lefrère Sr, Domenico Magro, Nicola Cantore, Meral Beksac, Zwi Berneman, Xavier Thomas, Lorella Melillo, Jose E. Guimaraes, Pietro Leoni, Mario Luppi, Maria E. Mitra,
Dominique Bron, Georges Fillet, Adriano Venditti, Marco Mancini, Joop Jansen, Marco Vignetti, Franco Mandelli, Theo de Witte

Administrative support: Liv Meert

Provision of study materials or patients: Roelof Willemze, Giovanna Meloni, Boris Labar, Jean-Pierre Marie, Constantijn J.M. Halkes, Petra Muus, Martin Mistrik, Sergio Amadori, Giorgina Specchia, Francesco Fabbiano, Francesco Nobile, Marco Sborgia, Andrea Camera, Dominik L.D. Selleslag, Francois Lefrère Sr, Domenico Magro, Simona Sica, Nicola Cantore, Meral Beksac, Zwi Berneman, Xavier Thomas, Lorella Melillo, Jose E. Guimaraes, Pietro Leoni, Mario Luppi, Maria E. Mitra, Dominique Bron, Georges Fillet, Erik W.A. Marijt, Adriano Venditti, Anne Hagemeijer, Sylvia M. Trisolini, Franco Mandelli, Theo de Witte Collection and assembly of data: Stefan Suciu, Giovanna Meloni, Boris Labar, Constantijn J.M. Halkes, Petra Muus, Francesco Fabbiano, Francesco Nobile, Marco Sborgia, Andrea Camera, Dominik L.D. Selleslag, Francois Lefrère Sr, Domenico Magro, Simona Sica, Nicola Cantore, Meral Beksac, Zwi Berneman, Xavier Thomas, Lorella Melillo, Jose E. Guimaraes, Pietro Leoni, Mario Luppi, Maria E. Mitra, Dominique Bron, Georges Fillet, Adriano Venditti, Anne Hagemeijer, Marco Mancini, Joop Jansen, Daniela Cilloni, Liv Meert, Paola Fazi, Marco Vignetti, Sylvia M. Trisolini

Data analysis and interpretation: Roelof Willemze, Stefan Suciu, Giovanna Meloni, Jean-Pierre Marie, Petra Muus, Erik W.A. Marijt, Anne Hagemeijer, Joop Jansen, Paola Fazi, Marco Vignetti, Theo de Witte

Manuscript writing: All authors Final approval of manuscript: All authors

\section{REFERENCES}

1. Burnett $A$, Wetzler M, Löwenberg B: Therapeutic advances in acute myeloid leukemia. J Clin Oncol 29:487-494, 2011

2. Mandelli F, Vignetti M, Suciu S, et al: Daunorubicin versus mitoxantrone versus idarubicin as induction and consolidation chemotherapy for adults with acute myeloid leukemia: The EORTC and GIMEMA Groups Study AML-10. J Clin Oncol 27: 5397-5403, 2009

3. Rudnick SA, Cadman EC, Capizzi RL, et al: High dose cytosine arabinoside (HDARAC) in refractory acute leukemia. Cancer 44:1189-1193, 1979

4. Willemze R, Zwaan FE, Keuning JJ, et al: Treatment of refractory acute leukaemia with high dose cytosine arabinoside. Br J Haematol 51:497-498, 1982

5. Herzig $\mathrm{RH}$, Lazarus HM, Wolff $\mathrm{SN}$, et al: High-dose cytosine arabinoside therapy with and without anthracycline antibiotics for remission reinduction of acute nonlymphoblastic leukemia. J Clin Oncol 3:992-997, 1985

6. Wolff SN, Marion J, Stein RS, et al: High-dose cytosine arabinoside and daunorubicin as consolidation therapy for acute nonlymphocytic leukemia in first remission: A pilot study. Blood 65:1407-1411, 1985

7. Phillips GL, Reece DE, Shepherd JD, et al: High-dose cytarabine and daunorubicin induction and postremission chemotherapy for the treatment of acute myelogenous leukemia in adults. Blood 77:1429-1435, 1991
8. Mayer RJ, Davis RB, Schiffer CA, et al: Intensive postremission chemotherapy in adults with acute myeloid leukemia: Cancer and Leukemia Group B. N Engl J Med 331:896-903, 1994

9. Bradstock KF, Matthews JP, Lowenthal RM, et al: A randomized trial of high- versus conventional-dose cytarabine in consolidation chemotherapy for adult de novo acute myeloid leukemia in first remission after induction therapy containing high-dose cytarabine. Blood 105:481-488, 2005

10. Schaich M, Röllig C, Soucek $S$, et al: Cytarabine dose of $36 \mathrm{~g} / \mathrm{m}^{2}$ compared with $12 \mathrm{~g} / \mathrm{m}^{2}$ within first consolidation in acute myeloid leukemia: Results of patients enrolled onto the prospective randomized AML96 study. J Clin Oncol 29:2696-2702, 2011

11. Miyawaki $S$, Ohtake $S$, Fujisawa $S$, et al: $A$ randomized comparison of 4 courses of standarddose multiagent chemotherapy versus 3 courses of high-dose cytarabine alone in postremission therapy for acute myeloid leukemia in adults: The JALSG AML201 study. Blood 117:2366-2372, 2011

12. Farag SS, Ruppert AS, Mrózek K, et al: Outcome of induction and postremission therapy in younger adults with acute myeloid leukemia with normal karyotype: A Cancer and Leukemia Group B study. J Clin Oncol 23:482-493, 2005

13. Löwenberg B: Sense and nonsense of highdose cytarabine for acute myeloid leukemia. Blood 121:26-28, 2013

14. Bishop JF, Matthews JP, Young GA, et al: A randomized study of high-dose cytarabine in induction in acute myeloid leukemia. Blood 87:1710-1717, 1996
15. Weick JK, Kopecky KJ, Appelbaum FR, et al: $A$ randomized investigation of high-dose versus standard-dose cytosine arabinoside with daunorubicin in patients with previously untreated acute myeloid leukemia: A Southwest Oncology Group study. Blood 88:2841-2851, 1996

16. Büchner $T$, Berdel WE, Schoch $C$, et al: Double induction containing either two courses or one course of high-dose cytarabine plus mitoxantrone and postremission therapy by either autologous stem-cell transplantation or by prolonged maintenance for acute myeloid leukemia. J Clin Oncol 24:2480-2489, 2006

17. Löwenberg $B$, Pabst $T$, Vellenga $E$, et al: Cytarabine dose for acute myeloid leukemia. N Engl J Med 364:1027-1036, 2011

18. Cheson BD, Cassileth PA, Head DR, et al: Report of the National Cancer Institute-sponsored workshop on definitions of diagnosis and response in acute myeloid leukemia. J Clin Oncol 8:813-819, 1990

19. Kalbfleisch JD, Prentice RL: The Statistical Analysis of Failure Time Data (ed 2). Hoboken, NJ, John Wiley \& Sons, 2002

20. Suciu S, Mandelli F, de Witte T, et al: Allogeneic compared with autologous stem cell transplantation in the treatment of patients younger than 46 years with acute myeloid leukemia (AML) in first complete remission (CR1): An intention-to-treat analysis of the EORTC/GIMEMA AML-10 trial. Blood $102: 1232-1240,2003$

\section{Affiliations}

Roelof Willemze, Constantijn J.M. Halkes, and Erik W.A. Marijt, Leiden University Medical Center, Leiden; Petra Muus, Joop Jansen, and Theo de Witte, Radboud University Nijmegen Medical Center, Nijmegen, the Netherlands; Stefan Suciu and Liv Meert, European Organisation for Research and Treatment of Cancer Headquarters; Dominique Bron, Hôpital Universitaire, Bordet-Erasme, Brussels; Dominik L.D. Selleslag, Algemeen Ziekenhuis Sint-Jan, Brugge; Zwi Berneman, Universitair Ziekenhuis, Antwerpen; Georges Fillet, Centre Hospitalier Universitaire du Sart-Tilman, Liège; Anne Hagemeijer, Center for Human Genetics, University of Leuven, Leuven, Belgium; Giovanna Meloni, Marco Mancini, Silvia Maria Trisolini, and Franco Mandelli, “Sapienza” University; Sergio Amadori and Adriano Venditti, Tor Vergata University Hospital; 
Simona Sica, Università Cattolica del Sacro Cuore, Policlinico A. Gemelli; Paola Fazi and Marco Vignetti, Gruppo Italiano Malattie Ematologiche dell' Adulto Foundation, Central Office, Rome; Giorgina Specchia, Università degli Studi di Bari, Bari; Francesco Fabbiano, Ospedali Riuniti "Villa Sofia-Cervello"; Maria Enza Mitra, Policlinico "Paolo Giaccone," Palermo; Francesco Nobile, Azienda Ospedaliera Bianchi-MelacrinoMorelli, Reggio Calabria; Marco Sborgia, Azienda Unitá Sanitaria Locale di Pescara, Pescara; Andrea Camera, L'A.O. Universitaria-Università degli Studi di Napoli “Federico II,” Napoli; Domenico Magro, A.O. Pugliese Ciaccio, Catanzaro; Nicola Cantore, A.O. San Giuseppe Moscati, Avellino; Lorella Melillo, Istituto Di Ricovero e Cura a Carattere Scientifico Casa Sollievo della Sofferenza, San Giovanni Rotondo; Pietro Leoni, A.O. Nuovo Ospedale Torrette, Ancona; Mario Luppi, A.O. Universitaria di Modena, Modena; Daniela Cilloni, University of Torino, Torino, Italy; Boris Labar, University Hospital Center-Rebro, Zagreb, Croatia; Jean-Pierre Marie, Saint-Antoine Hospital, Assistance Publique-Hopitaux de Paris and University Paris 6; Francois Lefrère Sr, Necker Hospital, Paris; Xavier Thomas, Hopital Edouard Herriot, Lyon, France; Martin Mistrik, University Hospital, Bratislava, Slovak Republic; Meral Beksac, Ankara University, Ankara, Turkey; and Jose E. Guimaraes, Hospital S. Joao/Faculdade de Medicina do Porto, Porto, Portugal.

\section{Experience the Value of ASCO's Global Community}

ASCO is unique in that we are the only organization that encompasses all oncology subspecialties, allowing our members to grow from the professional and personal expertise of their colleagues worldwide and across disciplines.

Along with this multidisciplinary approach, ASCO membership offers you deep discounts on meeting registrations and premier publications like Journal of Clinical Oncology (JCO), as well as a host of other benefits, including:

- Advance access to Members-Only Housing for ASCO's Annual Meeting

- 20\%-50\% off all ASCO University ${ }^{\circledR}$ resources, including ASCO-SEP ${ }^{\circledR}$ and the Oncology Literature Reviews

- Online advocacy tools like the ASCO ACT Network

For a full list of benefits specific to your membership category, visit benefits.asco.org. 


\section{Acknowledgment}

We thank the clinicians, nurses, and data managers of the 64 institutions who entered their patients into the EORTC-GIMEMA AML-12 study and provided the necessary data to make this study possible. In addition we are grateful to those who spent their time to quality control tasks. Finally the study could not have been a success without the continuous efforts of the members of the EORTC and GIMEMA data centers.

\section{Appendix}

The following is a list participating centers and participants: European Organisation for Research and Treatment of Cancer (EORTC) Leukemia Group: University Hospital Center Rebro, Zagreb, Croatia (B. Labar, I. Aurer); Saint-Antoine Hospital, Assistance PubliqueHopitaux de Paris \& University Paris 6, Paris, France (J.P. Marie, A. Vekhoff); Leiden University Medical Center, Leiden, the Netherlands (C.J.M. Halkes, W.A.F. Marijt, R. Willemze); Radboud University Nijmegen Medical Center, Nijmegen, the Netherlands (P. Muus, T. de Witte, J. Jansen); University Hospital, Bratislava, Slovak Republic (M. Mistrik); Algemeen Ziekenhuis Sint-Jan, Brugge, Belgium (D.L.D. Selleslag); Necker Hospital, Paris, France (F. Lefrère Sr); Ankara University, Ankara, Turkey (M. Beksac); Universitair Ziekenhuis, Antwerpen, Belgium (Z. Berneman); Hopital Edouard Herriot, Lyon, France (X. Thomas, Y. Chelghoum, M. Michallet); Hospital S. Joao/Faculdade de Medicina do Porto, Porto, Portugal (J.E. Guimaraes); Hôpital Universitaire Bordet-Erasme, Brussels, Belgium (D. Bron, W. Feremans); Centre Hospitalier du Sart Tilman, University of Liège, Liège, Belgium (G. Fillet); Maxima Medisch Centrum Veldhoven, Veldhoven, the Netherlands (G. Vreugdenhil); Jeroen Bosch Medisch Centrum, 's-Hertogenbosch, the Netherlands (H. Sinnige, J. Pruijt); Centre Hospitalier Régional La Citadelle, Liège, Belgium (B. De Prijck); Universitätsklinik, Innsbruck, Austria (R. Stauder); Institute Hematology, Prague, Czech Republic (J. Cermak); Onze Lieve Vrouwe Gasthuis, Amsterdam, the Netherlands (K. Roozendaal, P.J. De Valk); Ziekenhuisnetwerk Antwerpen, Middelheim, Belgium (R. De Bock); GIMEMA: "Sapienza” University, Department of Cellular Biotechnologies and Hematology, Rome, Italy (F. Mandelli, G. Meloni, R. Foà, S.M. Trisolini); Member of EORTC and GIMEMA: Tor Vergata University Hospital, Rome, Italy (S. Amadori, F. Buccisano, I. Del Principe, A. Venditti); Università degli Studi di Bari “Aldo Moro,” Bari, Italy (G. Specchia, D. Pastore); Ospedali Riuniti "Villa Sofia-Cervello,” Palermo, Italy (S. Mirto, F. Fabbiano, S. Magrin); Azienda Ospedaliera (A.O.) "Bianchi-Melacrino-Morelli,” Reggio Calabria, Italy (F. Nobile, F. Ronco, D. Vincelli, C. Alati, P. Cufari); Azienda Unitá Sanitaria Locale di Pescara, Pescara, Italy (G. Fioritoni, M. Sborgia); Università degli Studi di Napoli "Federico II," Napoli, Italy (B. Rotoli, F. Pane, A. Camera); A.O. Pugliese Ciaccio-Presidio Ospedaliero A. Pugliese, Catanzaro, Italy (A. Peta, S. Molica, D. Magro); Università Cattolica del Sacro Cuore-Policlinico A. Gemelli, Roma, Italy (G. Leone, S. Sica, F. Sorà); A.O. S.G. Moscati, Avellino, Italy (N. Cantore, G. Storti); Ospedale Istituto Di Ricovero e Cura a Carattere Scientifico Casa Sollievo della Sofferenza, San Giovanni Rotondo, Italy (N. Cascavilla, L. Melillo, D. Valente); A.O.-Nuovo Ospedale “Torrette,” Ancona, Italy (P. Leoni, D. Capelli); A.O.-Universitaria di Modena, Modena, Italy (G. Torelli, M. Luppi, M. Morselli); Policlinico "Paolo Giaccone," Palermo, Italy (V. Abbadessa, E. Mitra); Plesso Ospedaliero “A. Tortora” del DEA Nocera-Pagani, Nocera Inferiore, Italy (A.M. D’Arco, V. Belsito, S. Prisco, C. Ingenito); Ospedale “A. Businco," Cagliari, Italy (E. Angelucci, C. Romani, R. Murru); Ospedale “Santa Maria Goretti,” Latina, Italy (A. De Blasio, A. Centra); Complesso Ospedaliero S. Giovanni Addolorata, Roma, Italy (L. Annino, A. Chierichini); Ospedale S. Eugenio, Roma, Italy (P. De Fabritiis, B. Neri, V. Velotta); A.O.-Arcispedale S. Anna, Ferrara, Italy (A. Cuneo, M. Ciccone, O. Soffritti); A.O.-S.S. Antonio e Biagio e Cesare Arrigo, Alessandria, Italy (A. Levis, L. Depaoli); Università degli Studi di Parma, Parma, Italy (V. Rizzoli, C. Caramatti, M. Crugnola, E. Rossetti); A.O. Ospedali Riuniti “Papardo Piemonte,” Messina, Italy (M. Brugiatelli, P. Terrizzi); Ospedale S. Luigi Gonzaga, Orbassano, Italy (G. Saglio, D. Cilloni, E. Messa, C. Zanone); Ospedali Riuniti, A.O. di Foggia, Foggia, Italy (S.F. Capalbo); Università di Pisa-A.O. Pisana, Pisa, Italy (M. Petrini, S. Galimberti, E. Sordi); Ospedale San Carlo, Potenza, Italy (A. Olivieri, M. Pizzuti); Istituti Fisioterapici Ospitalieri, Istituto Nazionale Tumori Regina Elena, Roma, Italy (M.C. Petti, A. Spadea); Ospedale Santa Croce, Cuneo, Italy (A. Gallamini, D. Mattei); Ospedale A. Perrino, Brindisi, Italy (G. Quarta, A. Romano); Cancer Center Humanitas, Rozzano, Italy (A. Santoro, E. Todisco); Università degli Studi di Torino-“Città della Salute e della Scienza,” Torino, Italy (M. Boccadoro, D. Ferrero); A.O. "Sant' Andrea,” Roma, Italy (B. Monarca, A. Ferrari); Ist. Scientifico Ospedale San Raffaele, Milano, Italy (M. Bregni, F. Ciceri, M. Bernardi); Ospedale Di Ronciglione, Montefiascone (R.M.), Italy (M. Montanaro, V. Tini); Dipartimento di Scienze Biomediche, Università, Sassari, Italy (M. Longinotti, M.R. Nieddu, C. Fozza); Ospedale San Salvatore, Pesaro, Italy (G. Visani, G. Sparaventi); Università “Amedeo Avogadro," Novara, Italy (G. Gaidano, M. Lunghi); Ospedale S. Donato, Arezzo, Italy (A. Benci, A. Caremani); Istituti Ospitalieri, Cremona, Italy (S. Morandi, F. Lanza, C. Fiamenghi); Ospedale S. Camillo, Roma, Italy (I. Majolino, L. Pacilli, A. Proia); Università Campus Bio-Medico, Roma, Italy (G. Avvisati, O. Annibali); Ospedale "Infermi," Rimini, Italy (P. Fattori, P. Tosi); A.O. della Valtellina e della Valchiavenna, Sondalo, Italy (M. Balboni, A. Pastorini); Members of EORTC Headquarters: L. Meert, M. Dictus, L. Vanlanduyt, C. Vandermaelen, D. Rasier, G. Solbu, M.-P. Gauthier, H. Breyssens, M. Karrasch, S. Marreaud, S. Ramadan, and S. Suciu; Members of GIMEMA Central Office: P. Fazi, M. Vignetti, F. Cotugno, E. Criado, F. Paoloni; Members of the quality control committees: Leiden University Medical Center, the Netherlands (W.A.F. Marijt); University of Leuven, Belgium (A. Hagemeijer); Radboud University Nijmegen Medical Centre, Nijmegen, the Netherlands (J. Jansen); "Sapienza” University, Rome, Italy (M. Mancini, R. Foà, A. Vitale); Tor Vergata University Hospital, Rome, Italy (A. Venditti, L. Maurillo); Oncology Department, University of Torino, Italy (D. Cilloni, G. Saglio); Hematology Department, University of Bologna, Italy (N. Testoni); A.O.-Arcispedale S. Anna, Ferrara, Italy (A. Cuneo); Hematology, University Hospital, Perugia, Italy (C. Mecucci). 


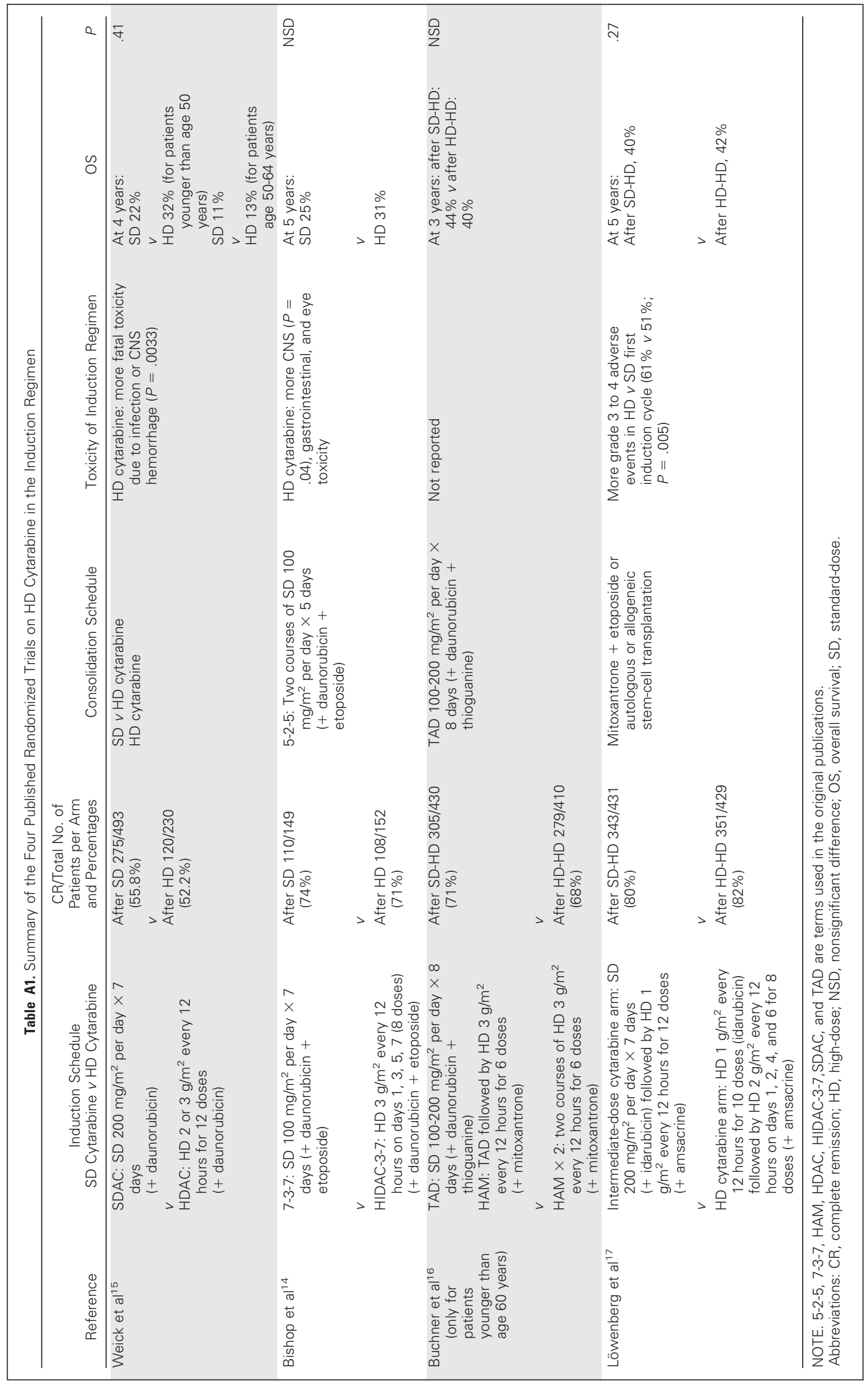

